\title{
EFFECT OF LOW TEMPERATURE PRE-TREATMENT ON ANTHER CULTURE IN SELECTED INDICA, JAPONICA RICE VARIETIES AND THEIR INTER SUB-SPECIFIC HYBRIDS
}

\author{
H. M. I. Herath ${ }^{1}$, D. C. Bandara ${ }^{2}$, P. K. Samarajeewa ${ }^{3}$ and D. S. A. Wijesundara ${ }^{4}$ \\ ${ }^{1}$ Postgraduate Institute of Agriculture, University of Peradeniya, Sri Lanka \\ ${ }^{2}$ Department of Agricultural Biology, Faculty of Agriculture, University of Peradeniya, Sri Lanka \\ ${ }^{3}$ Plant Genetic Resources Centre, Gannoruuwa, Peradeniya, Sri Lanka \\ ${ }^{4}$ Royal Botanic Gardens, Peradeniya, Sri Lanka \\ Accepted 14 May 2009
}

\begin{abstract}
Effect of cold pre-treatment of panicles with reduced temperatures (of $5^{\circ} \mathrm{C}, 7^{\circ} \mathrm{C}, 8^{\circ} \mathrm{C}$ and $10^{\circ} \mathrm{C}$ ) and exposure for different time durations (at weekly intervals up to 4 weeks) on anther culture of Japonica rice variety $\mathrm{Hu}$ lo tao, Indica rice varieties Bg 90-2, Bg 379-2 and their F1 hybrids for high frequency callus induction and plant regeneration was investigated. Anthers were cultured in N6 medium with 5\% sucrose, $2 \mathrm{mg} \mathrm{l}^{-1} 2,4 \mathrm{D}$ and $0.5 \mathrm{mg} \mathrm{l}^{-1}$ Kinetin. The cultures were kept in the dark at $28 \pm 2^{\circ} \mathrm{C}$ for callus induction. Induced calli of 1-2 mm diameter were transferred to half strength Murashige and Skoog (MS) medium supplemented with $2.0 \mathrm{mg} \mathrm{l}^{-1}$ Kinetin and $0.5 \mathrm{mg} \mathrm{l}^{-1} \mathrm{NAA}$. The effect of variety and cold pre-treatment was significant at $5 \%$ probability level. The Indica varieties had the lowest callus induction frequency $(0.3 \%$ 7.0\%). Japonica and Japonica $\times$ Indica hybrids had high callus induction $(12.3 \%-70.0 \%)$. The F1 hybrid Hu lo tao $\times$ Bg 90-2 had comparatively high callus induction (31.0\% - 70.0\%) than the other genotypes. Japonica variety $\mathrm{Hu}$ lo tao and F1 hybrids had highest callus development at cold pre-treatment at $8^{\circ} \mathrm{C}$ for 14 and 21 days. The highest green plant regeneration was observed in F1 hybrid, Hu lo tao $\times \mathrm{Bg}$ 90-2 followed by Japonica variety subjected to $8^{\circ} \mathrm{C}$ for 14 days. Very poor green plant regeneration was observed in Indica variety, Bg 90-2 when it was exposed to $7^{\circ} \mathrm{C}$ for 21 and 28 days. Variety Bg 379-2 did not produce any green plant at any treatment. The F1 hybrid Hu lo tao $\times \mathrm{Bg} 379-2$ produced lower green plants than F1 hybrid Hu lo tao $\times \mathrm{Bg} 90-2$. Cold pre treatment at $8^{\circ} \mathrm{C}$ temperature for 14 days was found to be most effective for anther culture in experimental genotypes used in the study.
\end{abstract}

Key words: variety, cold pre-treatment, callus induction, plant regeneration, rice

\section{INTRODUCTION}

Anther culture has become a powerful tool for the rapid production of haploid and inbred lines used for obtaining hybrid cultivars (Sopory and Munshi, 1996) and it has reduced the time required for breeding new cultivars by at least 3 to 5 years ( Tai, 2003). Androgenesis results in homozygous progeny from a heterozygous parent in a single generation and provides excellent material for research, plant breeding and plant transformation (Wang et .al., 2000). Production of haploids and dihaploid plants have been useful in providing access to recessive genes and for biotechnological manipulations (Sopory and Munshi, 1996). The populations derived from anther culture have enabled basic researchers to map molecular markers and characterize genetically complex traits while using as a tool for cultivar development (Tai, 2003).

The practical application of androgenetic haploids in rice improvement is still limited by the low regeneration and low number of doubled haploids recovered, particularly in Indica type (Senadhira et. al., 2002). As Zhang (1989) stated, making cross combinations among parents with different anther culture abilities may contribute to overcome anther culture difficulties. As Maheshwari et. al., (1980) stated, certain physical and chemical treatments given to flower buds or anthers prior to culture, can be highly inductive to the development of pollen into plants. The most significant is cold treatment. According to Genovesi and Magill (1979), cold treated anthers containing uninucleate microspores form callus at a much higher rate in rice.

\footnotetext{
*Corresponding Author’s email: indra_herath@yahoo.com
} 
The aim of this study was to determine the optimum cold pre treatment temperature and time duration required for anther culture in selected Japonica, Indica rice varieties and their F1 hybrids for high frequency callus induction and plant regeneration.

\section{MATERIALS AND METHODS}

\section{Plant material}

Seeds of Japonica parent $\mathrm{Hu}$ lo tao and Indica parents Bg 90-2, Bg 379-2 and their F1 hybrids were grown under standard agronomic practices in a green house.

\section{Anther pre treatment}

First two to three panicles from plants of each genotype were harvested between 9.00 to10.00 a.m. on sunny days. Panicles were harvested when the distance between collar of flag leaf and penultimate leaf was about 5-7 cm (Croughan, 1998) and the anthers were at uninucleate stage (microscopic observation). Panicles were wrapped in aluminium foil with a moistened cotton plug at the base and sealed in polypropylene bags separately. Forty panicles per each genotype per treatment were stored in cold temperatures of $5^{0} \mathrm{C}, 7^{0} \mathrm{C}, 8^{0} \mathrm{C}$, and $10^{\circ} \mathrm{C}$. Ten panicles per each genotype at each cold pre treatment temperature were taken out at weekly intervals for 4 weeks.

\section{Anther culture}

Spike lets were cut at the base and the anthers gently squeezed out with a needle. Hundred anthers were inoculated in $100<15 \mathrm{~mm}$ Petri dishes with agar solidified N6 medium supplemented with 2, 4-D $2.0 \mathrm{mg} \mathrm{l}^{-1}$, Kinetin 0.5 $\mathrm{mg} \mathrm{^{-1 }}$ and sucrose $5 \%$. One Petri dish constituted one replicate and an average of 5 replicates were cultured for each treatment. The cultures were placed in the dark at $28 \pm 2{ }^{0} \mathrm{C}$ (Chen et al., 1991) for callus induction. The cultures were examined at weekly intervals for six weeks and the percentage of anthers forming calli (callus induction frequency) was recorded after six weeks.

\section{Plant regeneration}

When the calli reached approximately $1-2$ mm diameter they were transferred to $100 \times 15$ $\mathrm{mm}$ Petri dishes containing $25 \mathrm{ml}$ of half strength Murashige and Skoog (MS) medium (Murashige and Skoog, 1962) supplemented with $2.0 \mathrm{mg} \mathrm{l}^{-1}$ Kinetin and $0.5 \mathrm{mg} \mathrm{l}^{-1}$ NAA (Croughan and Chu, 1991). The cultures were given a 16 hour photoperiod $\left(50 \mu \mathrm{E} \mathrm{m}^{-1} \mathrm{~S}^{1}\right)$.
Counts were made at weekly intervals and the data on percentage calli regenerating green and/ or albino plants was recorded after 6 weeks of incubation. The experiment was repeated thrice and the mean was taken for analyses.

The regenerated shoots were transferred to hormone free half strength MS medium for rooting. Regenerated plants were acclimatized and grown to maturity in a green house under standard agronomic practices.

\section{Data analysis}

Data analysis was done by the Statistical Analysis System (Release 9.1), Analysis of Variance (ANOVA). Mean separation was done by Duncan's Multiple Range Test (DMRT). All experiments were analyzed as a Completely Randomized Design.

\section{RESULTS}

\section{Effect of cold pre treatment on callus induction}

Callus induction started three weeks after culture establishment. High callus induction frequency was observed in Japonica parent and Japonica $x$ Indica hybrids than the Indica parents. The effect of variety and cold pre treatment was significant $(\mathrm{p}<0.05)$ for the callus induction frequency. Similarly, the interaction effect of the above two factors was significant at $5 \%$ significance level. Significant genotype $x$ pre treatment interaction implies that the determination of suitable pre treatment condition has the ability to further increase the responsiveness in both genetically high and low responsive genotypes. In this experiment Indica cultivars had the lowest callus induction frequency (ranging from $0.3 \%-7.0 \%$ ) while Japonica and Japonica $\times$ Indica hybrids had comparatively high (ranging from 12.3\% $70.0 \%$ ) callus induction frequency. Both F1 hybrids had high callus induction frequency than the Japonica and Indica parents. The F1 hybrid Hu lo tao $\times \mathrm{Bg} 90-2$ had high callus induction frequency $(31.0 \%-70.0 \%)$ than the other genotypes.

There was no callus development observed (Table 1) in the anthers without cold pre treatment (T1). Cold pre treatment for 7 days at $7^{0} \mathrm{C}$ had the lowest callus induction frequency in all the genotypes compared to other cold pre treatment days. It implies that the application of cold pre treatment for 7 days is not adequate. Callus induction frequency increased with pre 
treatment duration up to 21 days at $8^{\circ} \mathrm{C}$ in variety $\mathrm{Hu}$ lo tao and F1 hybrids. However, at 28 days of cold pre treatment the callus induction was reduced. Japonica variety $\mathrm{Hu}$ lo tao and F1 hybrids Hu lo tao $\times$ BG 90-2 and Hu lo tao $\times$ BG 379-2 had the highest callus development at cold pre treatment at $8^{\circ} \mathrm{C}$ for 7 to 28 days (T10 T12).

Table 1. Influence of cold pre-treatment on callus induction in anther cultures of selected Indica, Japonica rice varieties and their F1 hybrids.

\begin{tabular}{|c|c|c|c|c|c|c|c|}
\hline \multicolumn{3}{|c|}{ Treatment } & \multicolumn{5}{|c|}{ Mean Callus induction frequency } \\
\hline Code & $\begin{array}{c}\text { Temperature } \\
\text { C }^{\mathbf{0}}\end{array}$ & Days & Hu lo tao & Bg 90-2 & Bg 379-2 & $\begin{array}{c}\text { Hu lo tao } \\
90-2\end{array}$ & $\begin{array}{c}\text { Hu lo tao } \times \text { Bg } \\
379-2\end{array}$ \\
\hline$\overline{\mathrm{T} 1}$ & Room temp. & 0 & $0.0^{\mathrm{k}}$ & $0.0^{\mathrm{f}}$ & $0.0^{\mathrm{g}}$ & $0.0^{\mathrm{h}}$ & $0.0^{\mathrm{h}}$ \\
\hline $\mathrm{T} 2$ & 5 & 7 & $16.3^{\text {gh }}$ & $3.3^{\mathrm{b}}$ & $4.6^{\mathrm{bc}}$ & $37.0^{\mathrm{d}}$ & $24.6^{\mathrm{e}}$ \\
\hline T3 & 5 & 14 & $15.0^{\mathrm{hi}}$ & $2.0^{\mathrm{C}}$ & $2.6^{\mathrm{e}}$ & $36.3^{\text {de }}$ & $23.3^{\text {ef }}$ \\
\hline $\mathrm{T} 4$ & 5 & 21 & $18.0^{\mathrm{fg}}$ & $0.6^{\text {def }}$ & $1.3^{\mathrm{f}}$ & $32.0^{\mathrm{f}}$ & $19.3^{\mathrm{g}}$ \\
\hline $\mathrm{T} 5$ & 5 & 28 & $19.0^{\mathrm{ef}}$ & $0.6^{\text {def }}$ & $1.0^{\mathrm{fg}}$ & $31.0^{\mathrm{fg}}$ & $19.6^{\mathrm{g}}$ \\
\hline T6 & 7 & 7 & $15.6^{\text {ghi }}$ & $1.6^{\mathrm{cd}}$ & $4.6^{\mathrm{bc}}$ & $28.0^{\mathrm{g}}$ & $20.0^{\mathrm{g}}$ \\
\hline T7 & 7 & 14 & $21.0^{\text {de }}$ & $3.3^{\mathrm{b}}$ & $6.6^{\mathrm{a}}$ & $33.3^{\text {ef }}$ & $30.0^{\mathrm{d}}$ \\
\hline T8 & 7 & 21 & $25.6^{\mathrm{c}}$ & $6.0^{\mathrm{a}}$ & $6.3^{\mathrm{a}}$ & $39.0^{\mathrm{d}}$ & $28.0^{\mathrm{d}}$ \\
\hline T9 & 7 & 28 & $23.0^{\mathrm{d}}$ & $7.0^{\mathrm{a}}$ & $5.6^{\mathrm{ab}}$ & $36.0^{\text {de }}$ & $21.3^{\mathrm{fg}}$ \\
\hline T10 & 8 & 7 & $25.6^{\mathrm{c}}$ & $3.3^{\mathrm{b}}$ & $4.6^{\mathrm{bc}}$ & $52.3^{\mathrm{b}}$ & $38.0^{\mathrm{C}}$ \\
\hline $\mathrm{T} 11$ & 8 & 14 & $30.0^{b}$ & $3.6^{\mathrm{b}}$ & $4.0^{\mathrm{cd}}$ & $67.3^{\mathrm{a}}$ & $43.6^{\mathrm{b}}$ \\
\hline T12 & 8 & 21 & $33.0^{\mathrm{a}}$ & $1.3^{\text {cde }}$ & $3.3^{\mathrm{de}}$ & $70.0^{\mathrm{a}}$ & $47.6^{\mathrm{a}}$ \\
\hline T13 & 8 & 28 & $28.6^{\mathrm{b}}$ & $0.6^{\text {def }}$ & $2.6^{\mathrm{e}}$ & $69.0^{\mathrm{a}}$ & $43.6^{\mathrm{b}}$ \\
\hline $\mathrm{T} 14$ & 10 & 7 & $14.0^{\mathrm{hij}}$ & $1.0^{\text {cdef }}$ & $0.6^{\mathrm{fg}}$ & $51.3^{\mathrm{b}}$ & $28.0^{\mathrm{d}}$ \\
\hline T15 & 10 & 14 & $13.6^{\mathrm{ij}}$ & $0.3^{\text {def }}$ & $1.3^{f}$ & $46.0^{\mathrm{C}}$ & $29.0^{\mathrm{d}}$ \\
\hline T16 & 10 & 21 & $14.6^{\text {hij }}$ & $0.6^{\text {def }}$ & $1.0^{\mathrm{fg}}$ & $38.6^{d}$ & $19.3^{\mathrm{g}}$ \\
\hline T17 & 10 & 28 & $12.3^{\mathrm{j}}$ & $0.6^{\text {def }}$ & $0.3^{\mathrm{fg}}$ & $37.6^{\mathrm{d}}$ & $18.3^{\mathrm{g}}$ \\
\hline
\end{tabular}

In each column means followed by the same letters are not significantly different $(\mathrm{p}<0.05)$
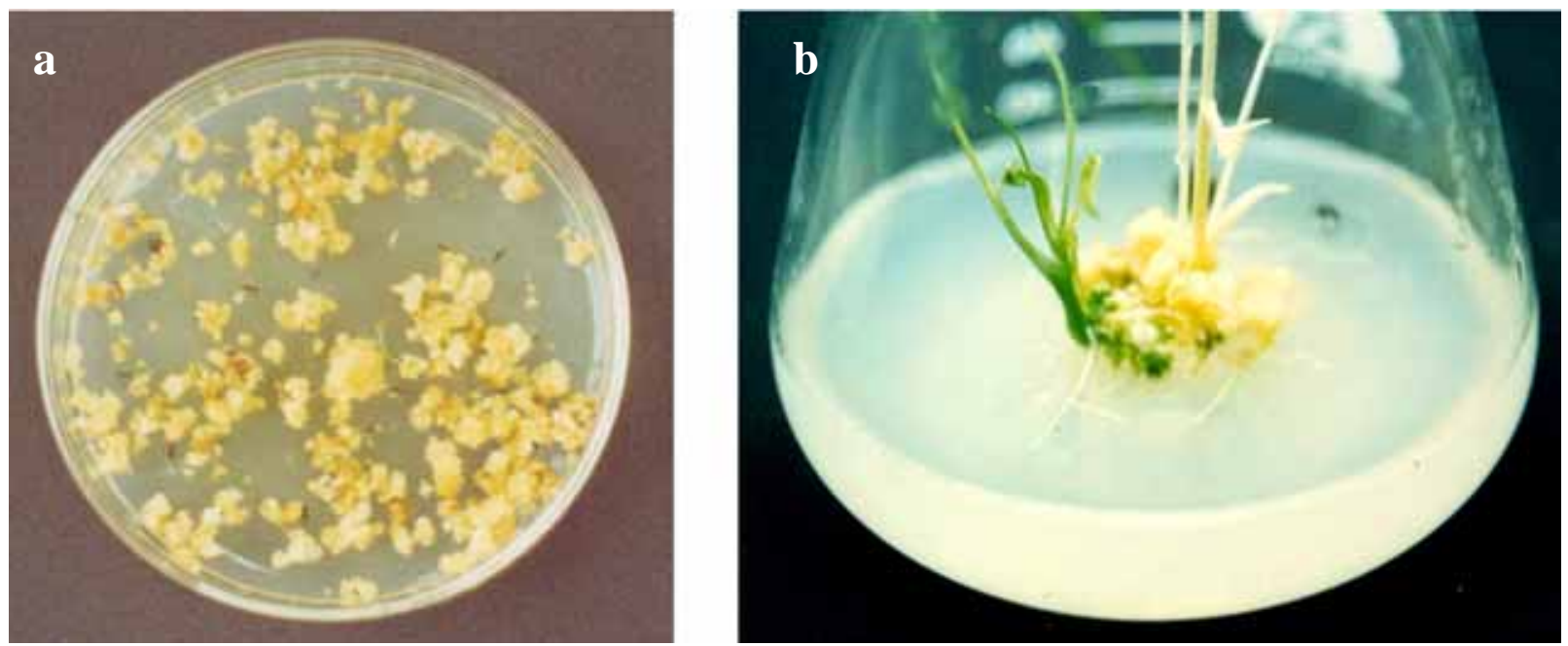

Figure 1. Anther culture response in $\mathrm{Hu}$ lo tao $\times \mathrm{Bg}$ 90-2 hybrid: (a) Callus development after three weeks in culture establishment and (b) Green and albino plant regeneration from callus after three weeks in calli transfer. 


\section{Plant regeneration from anther derived calli}

Plant regeneration started after two weeks from transfer of calli to the plant regeneration medium (Figure 1a). Some calli regenerated both green and albino plantlets (Figure 1b). Plant regeneration was greatly affected by the cold pre treatment application. The green plant regeneration was significantly $(\mathrm{p}<0.05)$ reduced with the increase of pre treatment duration at $8^{\circ}$ $\mathrm{C}$ cold pre treatment in $\mathrm{Hu}$ lo tao and F1 hybrids (Table 2).
Plant regeneration of Japonica parent and F1 hybrids was higher than the Indica parents. Relatively high plant regeneration was observed in F1 hybrid Hu lo tao $\times$ BG 90-2 than in Indica, Japonica parents and F1 hybrid Hu lo tao $\times$ BG 379-2. Highest green plant regeneration was observed in Japonica variety and F1 hybrids subjected to $8^{\circ} \mathrm{C}$ for 14 days.

Table 2. Influence of cold pre-treatment on plant regeneration in anther cultures of selected Indica, Japonica rice varieties and their $\mathrm{F} 1$ hybrids. ( $G$ - green, A - albino)

\begin{tabular}{|c|c|c|c|c|c|c|c|c|c|c|c|c|}
\hline \multirow{3}{*}{ Code } & \multicolumn{2}{|l|}{ Treatment } & \multicolumn{10}{|c|}{ Percentage Calli Regenerating Plants } \\
\hline & $\begin{array}{c}\text { Temperature } \\
\mathbf{C}^{\mathbf{0}}\end{array}$ & Days & \multicolumn{2}{|c|}{ Hu lo tao } & \multicolumn{2}{|c|}{ BG 90-2 } & \multicolumn{2}{|c|}{ BG 379-2 } & \multicolumn{2}{|c|}{$\begin{array}{c}\text { Hu lo tao } \\
\text { BG 90-2 }\end{array}$} & \multicolumn{2}{|c|}{$\begin{array}{c}\text { Hu lo tao } \\
\text { BG 379-2 }\end{array}$} \\
\hline & & & G & A & G & A & G & A & G & A & G & A \\
\hline $\mathrm{T} 1$ & Room temp. & 0 & - & - & - & - & - & - & - & - & - & - \\
\hline $\mathrm{T} 2$ & 5 & 7 & $23.1^{\mathrm{c}}$ & $20.2^{\mathrm{h}}$ & - & - & - & - & $49.1^{\mathrm{c}}$ & $47.0^{\mathrm{C}}$ & $10.3^{\mathrm{c}}$ & $14.3^{\mathrm{a}}$ \\
\hline Т3 & 5 & 14 & $20.3^{f}$ & $16.1^{\mathrm{m}}$ & - & - & - & - & $48.2^{\mathrm{d}}$ & $50.6^{\mathrm{b}}$ & $11.6^{\mathrm{b}}$ & $13.3^{\mathrm{ab}}$ \\
\hline $\mathrm{T} 4$ & 5 & 21 & $17.1^{\mathrm{j}}$ & $18.1^{\mathrm{k}}$ & - & & - & - & $31.3^{\mathrm{j}}$ & $43.6^{\mathrm{e}}$ & $9.3^{\mathrm{d}}$ & $10.6^{\text {de }}$ \\
\hline T5 & 5 & 28 & $16.0^{\mathrm{l}}$ & $19.7^{\mathrm{ij}}$ & - & - & - & - & $29.2^{1}$ & $38.6^{\mathrm{g}}$ & $7.3^{\mathrm{fg}}$ & $10.3^{\mathrm{de}}$ \\
\hline T6 & 7 & 7 & $22.0^{\mathrm{C}}$ & $21.0^{\mathrm{fg}}$ & - & - & - & - & $47.1^{\mathrm{e}}$ & $44.0^{\mathrm{e}}$ & $10.3^{c}$ & $12.3^{\mathrm{bc}}$ \\
\hline T7 & 7 & 14 & $23.0^{c}$ & $21.3^{\mathrm{ef}}$ & - & - & - & - & $46.2^{f}$ & $47.6^{\mathrm{C}}$ & $9.3^{\mathrm{d}}$ & $10.3^{\text {de }}$ \\
\hline T8 & 7 & 21 & $16.3^{\mathrm{k}}$ & $19.3^{\mathrm{j}}$ & $2.3^{\mathrm{a}}$ & $3.8^{\mathrm{b}}$ & - & $1.2^{\mathrm{b}}$ & $38.3^{\mathrm{h}}$ & $45.3^{\mathrm{d}}$ & $8.3^{\mathrm{e}}$ & $9.6^{\mathrm{e}}$ \\
\hline T9 & 7 & 28 & $15.3^{\mathrm{m}}$ & $20.1^{\mathrm{hi}}$ & $2.1^{\mathrm{a}}$ & $4.2^{\mathrm{a}}$ & - & $2.1^{\mathrm{a}}$ & $30.1^{\mathrm{k}}$ & $49.6^{\mathrm{b}}$ & $10.0^{\mathrm{cd}}$ & $11.3^{\mathrm{cd}}$ \\
\hline $\mathrm{T} 10$ & 8 & 7 & $16.2^{\mathrm{kl}}$ & $17.1^{l}$ & - & - & - & - & $40.3^{g}$ & $40.0^{\mathrm{f}}$ & $12.3^{b}$ & $14.3^{\mathrm{a}}$ \\
\hline $\mathrm{T} 11$ & 8 & 14 & $28.7^{\mathrm{a}}$ & $25.2^{\mathrm{b}}$ & - & - & - & - & $64.8^{\mathrm{a}}$ & $59.0^{\mathrm{a}}$ & $14.3^{\mathrm{a}}$ & $12.3^{b c}$ \\
\hline $\mathrm{T} 12$ & 8 & 21 & $23.9^{\mathrm{b}}$ & $21.3^{\mathrm{ef}}$ & - & - & - & - & $57.3^{b}$ & $47.6^{\mathrm{c}}$ & $10.3^{c}$ & $12.3^{b c}$ \\
\hline T13 & 8 & 28 & $19.7^{\mathrm{g}}$ & $22.9^{c}$ & - & - & - & - & $35.8^{\mathrm{i}}$ & $49.6^{\mathrm{b}}$ & $6.6^{\text {gh }}$ & $9.6^{\mathrm{e}}$ \\
\hline $\mathrm{T} 14$ & 10 & 7 & $21.3^{\mathrm{e}}$ & $29.7^{\mathrm{a}}$ & - & - & - & - & $40.2^{\mathrm{g}}$ & $36.3^{\mathrm{h}}$ & $6.6^{\text {gh }}$ & $11.3^{\mathrm{cd}}$ \\
\hline $\mathrm{T} 15$ & 10 & 14 & $18.7^{\mathrm{i}}$ & $22.3^{d}$ & - & - & - & - & $29.3^{1}$ & $27.6^{\mathrm{j}}$ & $7.6^{\mathrm{ef}}$ & $14.3^{\mathrm{a}}$ \\
\hline T16 & 10 & 21 & $17.3^{\mathrm{j}}$ & $21.8^{\mathrm{e}}$ & - & - & - & - & $31.7^{\mathrm{j}}$ & $29.0^{\mathrm{i}}$ & $6.3^{\mathrm{n}}$ & $8.3^{f}$ \\
\hline $\mathrm{T} 17$ & 10 & 28 & $19.2^{\mathrm{h}}$ & $20.7^{\mathrm{g}}$ & - & - & - & - & $28.4^{\mathrm{m}}$ & $27.3^{\mathrm{j}}$ & $5.3^{\mathrm{i}}$ & $5.6^{\mathrm{h}}$ \\
\hline
\end{tabular}

In each column means followed by the same letters are not significantly different $(\mathrm{p}<0.05)$ 


\section{DISCUSSION}

High callus induction frequency and percent green plant regeneration were observed in Japonica and Japonica $\times$ Indica hybrids than in Indica parents. The difference between indica parents for anther culture response also affected its F1 hybrid response for anther culture. This implies that, the genotype is a critical impotent factor affecting androgenesis. Datta et. al., (1990) also reported that genotype is the most critical factor in obtaining good microsporogenesis.

The effect of variety, cold pre treatment and the interaction effect of the two factors were significant $(p<0.05)$ for the callus induction frequency. Datta (2005) reported that, the response to chilling or heating is also genotype dependent. As Sopory and Munshi (1996) stated, temperature is one of the most important factors that influences the induction of pollen embryo/ callus development. According to Reddy et al., (1985), pre treatment of anthers by low and elevated temperatures had stimulatory effect for callus induction and plantlet yield in rice.

Callus induction frequency increased with pre treatment duration up to 21 days at $8^{\circ} \mathrm{C}$ in variety $\mathrm{Hu}$ lo tao and $\mathrm{F} 1$ hybrids. The type, duration and the time of application of pretreatment vary with species or variety (Datta, 2001). Cold pre treatment was reported to have promontory effect for androgenesis in several plant species. Orbert et al. (2005) have reported that the induction of callus from cultured anthers of flax was highest after cold pre treatment for 7 days at $8^{\circ}$ C. According to Sato et al. (2002), incubation of buds or inflorescence at $4^{\circ} \mathrm{C}$ before the culture of microspores of Brassica rapa induced efficient microspore embryogenesis and prolonged pre treatment up to 20 days was effective for embryo induction. In soy bean, androgenic response was significantly increased with the time of exposure from 0 to 28 days at $4^{\circ} \mathrm{C}$ (Rodrigues et. al., 2005). Sato et al. (2002) observed that the microspores at the late unicellular stage before cold pre treatment in Brassica rapa were changed to bicellular stage. High percentage of bicellular stage microspores with equal size nuclei which is the first step in microspore embryogenesis was observed after the pre treatment. They have further explained that during low temperature treatment most microspores slowly develop to normal pollen while a small number of microspores develop to embryos. This may be the reason for promotive effect of low temperature pre treatment on microspore embryogenesis.

In this study, plant regeneration was greatly affected by the cold pre treatment application. According to Roininen et al. (2005), cold pre treatment of spikes increased green plant regeneration in anther culture of rye cultivars. Sopory and Munshi, (1996) have stated that high temperature may stimulate production of secondary embryos which may lack a normal regeneration capacity. In general, after 21 days of any of the cold treatments, anthers essentially produced albino plants. It could thus seem that the ability to produce green pigment is lost with time during cold storage (Genovesi and Magill, 1979). They have further explained that, during low temperature treatment most microspores slowly develop in to normal pollen while a small number of microspores develop to embryos. This may be the reason for promotive effect of low temperature pre treatment on microspore embryogenesis. According to Gupta and Borthakur (1987), although a cold shock for 25 days enhanced the frequency of callusing in rice, the plantlets regenerated from these microspores were mostly albinos. Similar results were obtained during this study with the extension of time of cold pre treatment.

\section{CONCLUSION}

Cold pre-treatment at $8^{\circ} \mathrm{C}$ for 14 days gave the best performance in callus induction and plant regeneration in selected Indica and Japonica parents and their F1 hybrids.

\section{REFERENCES}

Chen, C.C., Tsay, H.S. and Huang, C.R. (1991). Factors affecting androgenesis in rice (Oryza sativa L.). In: Y.P.S. Bajaj (Ed.).Biotechnology in Agriculture and Forestry (14): Rice., Springer Verlag. Berlin. 193-211.

Croughan, T.P. (1998). Anther culture for double haploid production.. In: O.L. Gamborg, and G.C. Phillips, (Eds.). Plant Cell Tissue and Organ Culture: Fundermental Methods. Narosa Publishing, New Delhi. 143-154.

Croughan, T.P. and Chu, Q.R. (1991). Rice (Oryza sativa L.) establishment of callus cultures and the regeneration of plants. In: Y.P.S. Bajaj(Ed.). Biotechnology in Agriculture and 
Forestry (14): Rice. Springer Verlag. Berlin. 1937.

Datta, S.K. (2005). Androgenic haploids: Factors controlling development and its application in crop improvement. Current Science. 89 (11): 1870-1878.

Datta, S.K. (2001). Androgenesis in Cereals. In : S. S. Bhojwani, and W. Y. Soh (Eds.). Current Trends in Embryology of Angiosperms. Kluwer Academic Publishers. 471-488.

Datta, S.K., Datta, K. and Potrykus, I. (1990). Embryogenesis and plant regeneration from microspores of both Indica and Japonica rice(Oryza sativa). Plant Science. 67: 83-88.

Genovesi, A.D. and Magill, C.W. (1979). Improved rate of callus and green plant production from rice anther culture following cold shck. Crop Sci. 19: 662-664.

Gupta, H.S. and Borthakur, D.N. (1987). Improved rate of callus induction from rice anther culture following microscopic staining of microspores in iron alum-haematoxylin. Theor. Appl. Genet. 74: 95-99.

Maheshwari, S.C. Tyagi, A.K. and Malhotra, K. and Sopory, S.K. (1980). Induction of haploid from pollen grains in angiosperms - the current status. Theor. Appl. Genet. 58: 193-206.

Murashige, T.P. and Skoog, F. (1962). A revised medium for rapid growth and bioassays with tobacco tissue culture. Physiol. Plant. 15(3): 473-497.

Obert, B., Dedieova, B., Hricova, A., Samaj, J. and Pretova, A. (2005). Flax anther culture: effect of genotype, cold treatment and media. Plant Cell Tissue and Organ Culture. 79(2): 233-238.

Reddy, V.S., Leelawathi, S. and Sen, S.K. (1985). Influence of genotype and culture medium on microspore callus induction and green plant regeneration in anthers of Oryza sativa. Physiol. Plant. 63: 309-314.

Rodrigues, L., Oliveira, J., Iranco, L. and Zanettini, M.B. (2005). Anther culture and cold treatment of floral buds increased symmetrical and extra nuclei frequencies in soybean pollen grains. Plant Cell Tissue and Organ Culture. 81(1): 101-104.

Roininen, I.T., Tanhuanpaa, P. and Immonen, S. (2005). The effect of cold and heat treatments on the anther culture response of diverse rye genotypes. Euphytica. 145(1-2): 1-9.

Sato, S., Katoh, N., Iwai, S. and Hagimori, M. (2002). Effect of low temperature pre treatment of buds or inflorescence on isolated microspore culture in Brassica rapa (syn. B. campestris). Breeding Sci. 52: 23-26.

Senadhira, D., Zapatha-Aris, F.J., Gregorio, G.B., Alejar, M.S., Cruz, H.C., Padolina, T.F. and Galvez, A.M., (2002). Development of the first salt-tolerant rice cultivar through indica/ indica anther culture. Field Crops Res. 76: 103110.

Sopory, S.K. and Munshi, M. (1996). Anther Culture. In: S.M. Jain, S.K. Sopory, and R.E. Veilleus (Eds.). In vitro Haploid Production in Higher Plats. Kluwer Academic Publishers, Netherland. 145-176.

Tai, T. H. (2003). Rice Biotechnology. In: G.W. Smith, and R. H. Dilday (Eds.). Rice; Origin, History, Technology and Production.. John Wiley and Sons, Inc. 203-220.

Wang, M., Sandra, V.B. and Bert, V.D. (2000). Insights in to a key developmental switch and its importance for efficient plant breeding. Plant Physiology. 124: 523-530.

Zhang, Z.H. (1989). The practicability of anther culture breeding in Rice. In: A. M. Kazi, and L. Stich (Eds.). Review of Advances in Plant Biotechnology, CIMMYT and IRRI. Philippine. 31-42. 